\title{
Regional Innovation Systems: Content and Evolution of Academic Research
}

\author{
Ekaterina Moskvitina \\ Financial University under the Government of the Russian \\ Federation \\ Moscow, Russian Federation \\ Email: kitkat_08@mail.ru

\section{Dmitry Morkovkin} \\ Financial University under the Government of the Russian \\ Federation \\ Moscow, Russian Federation \\ Email: MorkovkinDE@mail.ru
}

\author{
Pavel Stroev \\ Financial University under the Government of the Russian \\ Federation \\ Moscow, Russian Federation \\ Email: stroevpavel@gmail.com \\ Natalia Isaichykova \\ Gomel State Technical University named after P.O. Sukhoi \\ Gomel, Republic of Belarus \\ Email: natalyii@mail.ru
}

\begin{abstract}
The content and evolution of academic research on regional innovation systems from 1997 to 2018 are analyzed. The growing importance and relevance of the topic, in both practical and academic terms, are emphasized. Different approaches to define RIS and its components are summarized. Special attention is paid to research on models of regional innovation systems. Recommendations for future research are presented.
\end{abstract}

Keywords-spatial economy; regional innovation system; regional innovation subsystem; regional innovation policy; regional innovation collaboration; models of the regional innovation systems; regional systems of innovation

\section{INTRODUCTION}

The beginning of the 21 st century is the epoch of new revolutionary transformations caused by the emergence of the sixth technological order. Today the idea of globalization of economic processes, based on the principle of the international division of labor and the growth of the technological chain links due to outsourcing processes, is losing its significance. This is largely due to the fact that in developed countries innovative additive technologies continue to be widely adopted, which radically changes the structure of global value chains, and the fact that the further expansion of sales markets becomes impossible at some point in the context of globalization. Such changes make the old technological structure ineffective.

In the context of globalization "failures", the need for the development of a national economy and national economic systems is growing. The national economy is a multi-level system, therefore, regional economic subsystems, especially the regional innovation system, require no less attention from the state.

The concept of regional innovation system has been gaining much attention from academic researchers and policy makers since the early 1990s. This literature survey analyzes the content and evolution of academic research on regional innovation systems (RIS) from 1997 to 2018.

The fundamental researches in this field are the works of Cooke, Asheim, Coenen, Iammarino. They specify the key concepts of "region", "innovation" and "system"; define national and regional innovation systems and emphasize different aspects of RIS's development.

RISs were conceptualized by Cooke in 1997 as a "collective order based on micro-constitutional regulation" [10]. He explored the case for regional systems of innovation and emphasized the importance of financial capacity, institutionalized learning and productive culture to systemic innovation.

Later in 2001 Cooke presented a systematic account of the idea and content of regional innovation systems following discovers made by regional scientists, economic geographers and innovation analysts. One of the obvious conclusions to be drawn from his analysis is that regional innovation policy should stimulate the growth of strong private investing organizations that will have the profitmotive as the incentive to be more proactive than a public system has shown itself to be capable of [8].

It is also known that in 2005 Cooke redefined RIS as "interacting knowledge generation and exploitation subsystems linked to global, national and other regional systems" [9]. This definition affirmed the relations of RISs outside its own boundaries, and the interconnection with other types of innovation systems.

According to Asheim and Coenen, the regional innovation system can be thought of as the institutional infrastructure supporting innovation within the production structure of a region [1]. The researchers emphasized the need for "unpacking" the role of territorial agglomerations in promoting innovativeness and competitiveness by "digging" 
into the contingencies, particularities and specificities that characterize real world contexts where cluster and RIS policies are introduced and used.

The concept "regional innovation system" derives from the concept of national innovation system (NIS) focusing on a particular territory.

Iammarino noted, that NIS cannot by any means be considered as being the simple sum of regional systems, and identified two major problems in finding some kind of standardization of sub-national systems of innovation [12]:

The first one (theoretical in nature) arises from the fact that geographical innovation systems have been conceptualized and applied by considering components, relationships and attributes, which operate and are governed mainly at the national level.

The second problem (practically oriented) is the wellrecognized and broad regional measurement issue.

Further researches reviewed and summarized the most important ideas and arguments of the recent theorizing on regional innovation systems to provide the basis for a critical examination of such issues as:
- Definition confusion and empirical validation;

- The territorial dimension of regional innovation systems;

- The role of institutions.

Doloreux and Parto in the "Regional innovation systems: a critical review" presented a systemic account of the weaknesses and potentials of the regional innovation system as a concept, attempting to provide a few potentially fruitful points of departure for future research on this theme [11] The researches defined regional innovation systems as a set of interacting private and public interests, formal institutions and other organizations that function according to organizational and institutional arrangements and relationships conducive to the generation, use and dissemination of knowledge.

\section{FIVE BASIC APPROACHES OF RISS CATEGORIZED}

Since 2001 to 2015 RISs were categorized in five basic approaches (see "Fig. 1").

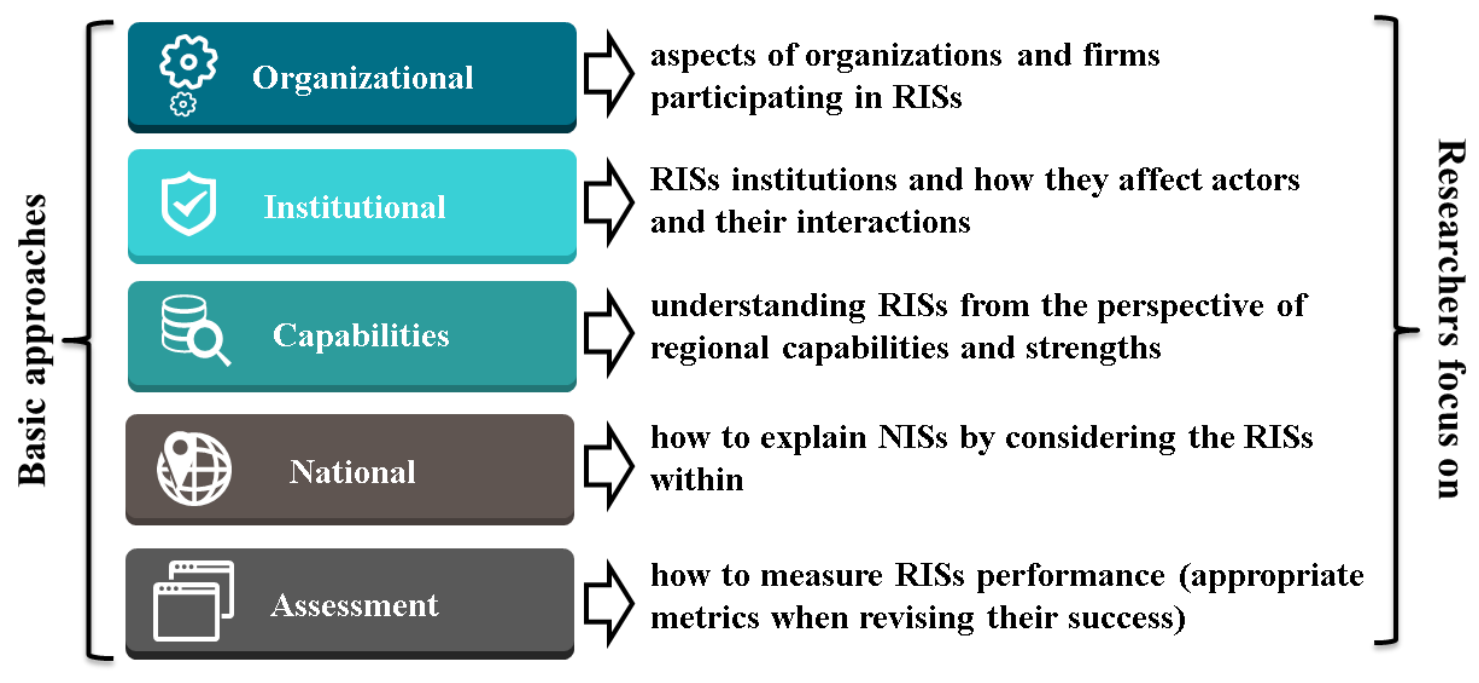

Fig. 1. Basic approaches to define RISs and its components

In the frame of the organizational approach researchers emphasize aspects of organizations and firms participating in RISs. In 2007 Christopherson and Clark in their work showed how firms actually behave in territorial innovation systems (IS) [6].

The institutional approach focuses on RISs institutions and how they affect actors and their interactions. Researches especially highlighted the role of a proactive public-private partnership and impact of the public sector and public policy support by acknowledging to a greater extent the importance of institutional complementarities in knowledge economies [2].
The capabilities approach seeks to understand RISs from the perspective of regional capabilities and strengths. Zhao, Cacciolatti, Lee and Song in their research proposed policy measures for improving regional innovation collaboration within China [18]. They analyzed regional collaborations on innovation to understand the dynamics of regional collaboration on innovation projects and capabilities.

\section{MAIN DIMENSIONS OF REGIONAL COLLABORATIONS AMONG ORGANIZATIONS}

The results of their work show that regional collaborations among organizations can be categorized by means of six main dimensions (see "Fig. 2"). 


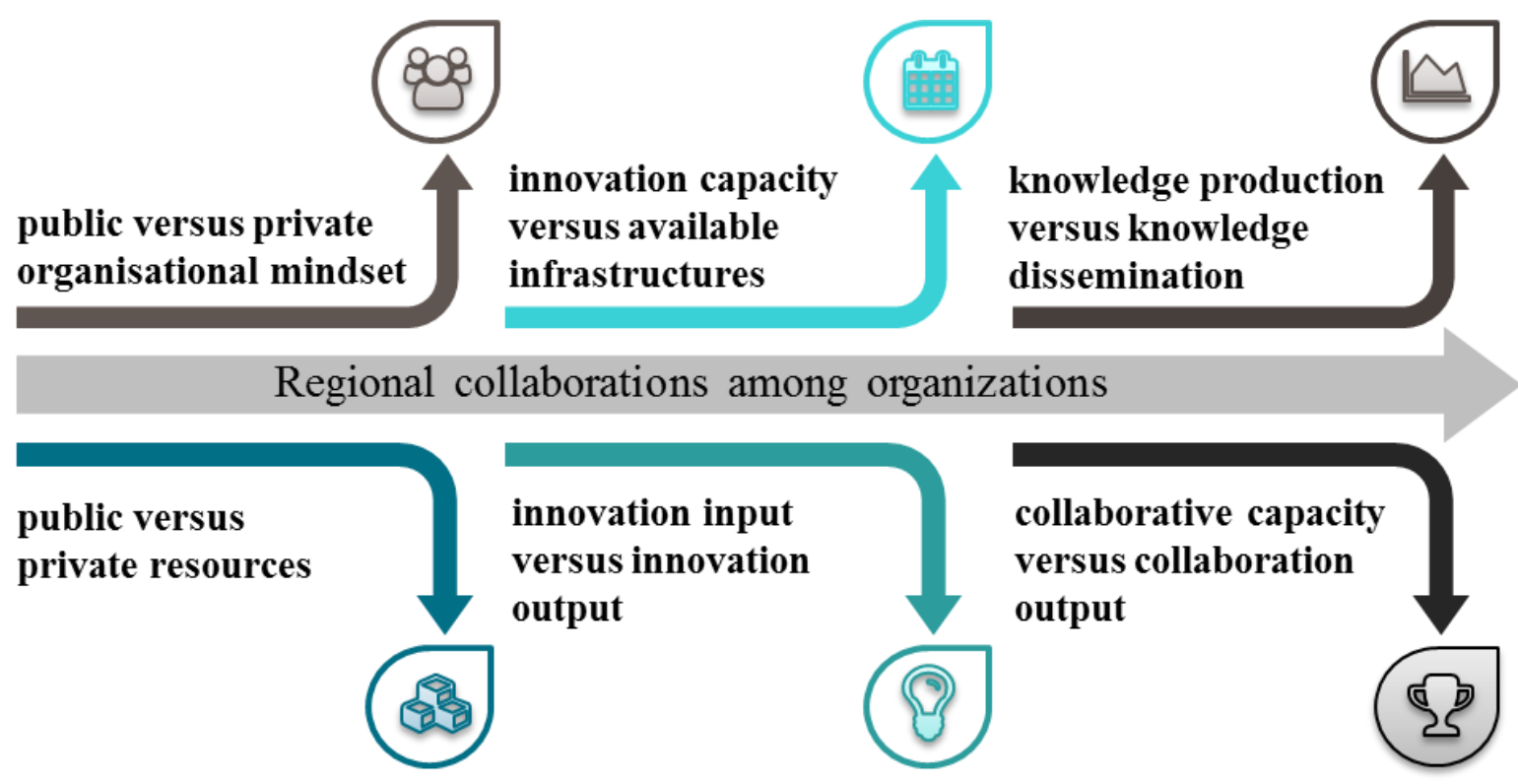

Fig. 2. Dimensions of regional collaborations among organizations.

Based on national approach authors focus on how to explain NISs by considering the RISs within. One of the interesting hypotheses of researches, who studied national and regional innovation systems in Hungary, is that the national level no longer adds to the synergy across these regional innovation systems [13].

The assessment approach focuses on how to measure RISs performance and the appropriate metrics when revising their success. Leydesdorff and Fritsch introduced a way of assessing the quality of regional innovation systems by measuring the interaction and synergy between subsystems by means of an indicator based on entropy statistics (the approach was applied to the various regions of Germany) [15].

From 2016 to 2017, one of the central question in discussing RISs and main actors was the role of universities. This problem was studied by Benneworth, Pinheiro and Karlsen; they concluded that universities play a significant role as scientific knowledge suppliers, as they support the development of regions [3].

Today one of the widely spread approach is considering RISs as complex adaptive systems. In 2018 Ponsiglione, Quinto and Zollo published the article in which they proposed an agent-based model to support the development of self-sustaining regional innovation systems (the case of European regions). Results of their research showed that the exploration capacity, the propensity to cooperation, and the endowed competencies of actors belonging to a region could be considered as key aspects in affecting the regional innovation performance [17].

To sum up different approaches, RIS can be defined as a network of institutions and actors of the state and non-state sectors, the interaction of which ensures the transformation of innovative tangible (financial, infrastructure, technical, etc.) and intangible (human capital) resources into innovative products and technologies.
In 2018 systematic literature reviews about RISs were published. Pino and Ortega systemized theoretical and practical materials from previous researches and gave recommendations for future research [16]. They analyzed the content and evolution of academic research on RIS from 1997 to September 2017; defined the components of an RIS; analyzed the relationship between IS, NIS, and RIS; presented what is known about how to measure performance of innovation systems. Their work contains the following recommendations for researchers:

- The definition of the formal and informal organizations and institutions operating at the interior of the RIS must be accompanied by an explanation of their necessary relations and interactions, as well as the physical or technological capabilities needed for the regional system's success;

- It is also important to define what success is for an RIS, including economic, ecological, and social aspects also recognizing the probability of better categorizing regions into different profiles rather than expecting every single RIS to present then same characteristics and behavior;

- It is important to learn more about the institutions related to the RIS, understanding how to classify them considering which ones positively and negatively influence innovation activity, considering which ones are meant to be conceive for the long term and which ones must work and adapt constantly, and considering the macroeconomic institutions operating at the sub-national level.

\section{DIFFERENT APPROACHES AT MODELS OF RIS}

Today, researchers pay great attention to the formation and development of regional innovation system. One of the most important issues that a number of authors are working 
on is forming the model of a regional innovation system. Existing research in this area allows defining key approaches to identifying and classifying models of regional innovation systems (see "Fig. 3").
APPROACH

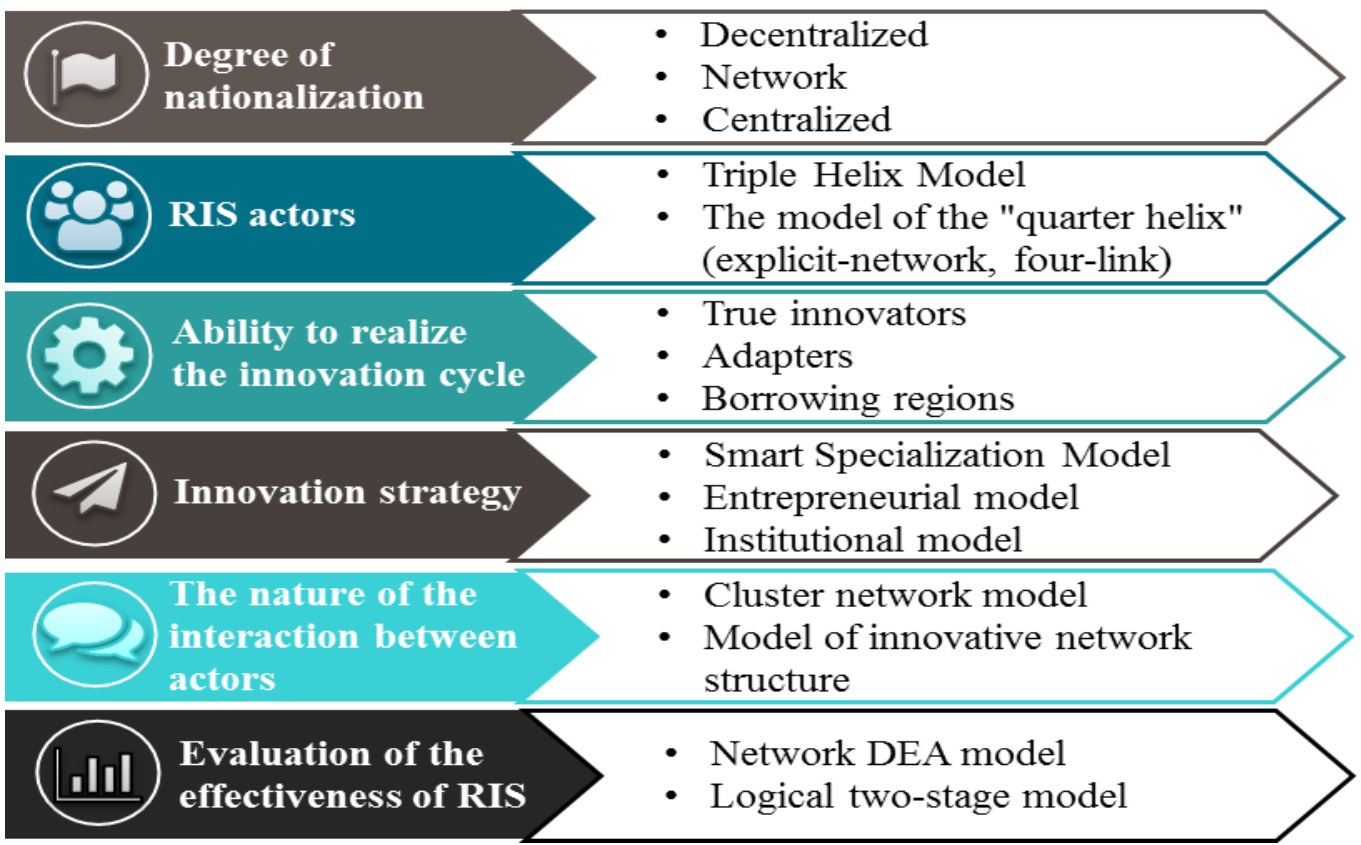

Fig. 3. Models of RIS: different approaches [4]; [5]; [7]; [14]; [18].

Speaking about the subject to future research, it is necessary to develop a model of the regional innovation system on the basis of identifying the parameters and indicators characterizing, on the one hand, the innovation and resource potential of the regional innovation system (for example, the proportion of organizations performing R\&D in the total number of organizations; internal R\&D costs; organizations engaged in the development of additive technologies in the following areas: robotics and 3D printing) and, on the other hand, effectiveness of its implementation (for example, the number of advanced production technologies created per 10 thousand people employed in the economy). The development of a methodological approach to assessing the basic parameters of a regional innovation system, determining the characteristics of its formation, will provide a "transparent picture" of weaknesses and strengths, opportunities and threats to the formation and development of a regional innovation system in the era of global technological change.

\section{CONCLUSION}

After evaluating the information available and the academic content about RISs, the growing importance and relevance of the topic, in both practical and academic terms can be emphasized:

- Firstly, the results of researches on regional innovation systems should form the basis of the state policy for managing regional innovation development, including the development of an innovation strategy and measures for its successful implementation;
- Secondly, information is valuable for other actors of the regional innovation system (for enterprises, universities, society represented by non-profit organizations, unions, etc.) primarily from the point of view of understanding the general vector of innovative development of the region, problems and prospects;

- Thirdly, the study of regional innovation systems (features of the formation and development of RIS, complex socio-economic relations between actors, the role of RIS in the development of NIS and the socioeconomic system of the country as a whole, etc.) contributes to the development of economic sciences and modern economic thought.

The important questions that remain to be answered are if RISs do contribute to long term socio-economic growth and how to measure the extent of their contribution. When having defined the concept of RIS, the issues which seem critical for further understanding and further work are the usage of indicators and metrics to measure the performance of RIS, its innovation potential and effectiveness of its implementation.

\section{REFERENCES}

[1] B.T. Asheim, L. Coenen. Regional Innovation Systems Policy: a Knowledge-based Approach. Circle, Lund University. 2005 (13).

[2] B.T. Asheim, J. Moodysson \& F. Tödtling. Constructing regional advantage: Towards state-of-the-art regional innovation system 
policies in Europe? European Planning Studies, 19 (7), 2011. 11331139.

[3] P. Benneworth, R. Pinheiro, \& J. Karlsen. Strategic agency and institutional change: Investigating the role of universities in regional innovation systems (RISs). Regional Studies, 51(2). 2017, pp. 235248.

[4] A. Bosch, N. Vonortas. Smart Specialization as a Tool to Foster Innovation in Emerging Economies: Lessons from Brazil. Foresight and STI Governance, vol. 13, 2019, No. 1, pp. 32-47.

[5] K. Chen, J. Guan. Measuring the Efficiency of China's Regional Innovation Systems: Application of Network Data Envelopment AnalysisDEA).-URL:

https://www.tandfonline.com/doi/abs/10.1080/00343404.2010.49747 9

[6] S. Christopherson, J. Clark. Power in firm networks: What it means for regional innovation systems. Regional Studies, 2007, 41(9), pp. 1223-1236

[7] P. Cooke. Introduction: origins of the concept // Braczyk H. J. et al. Regional Innovation Systems. The role of governances in a globalized world. London: UCL Press, 1998. P. 2-2.

[8] P. Cooke. Regional Innovation Systems, Clusters, and the Knowledge Economy. Oxford University Press, 2001, pp. 945-973.

[9] P. Cooke. Regionally asymmetric knowledge capabilities and open innovation. Research Policy, 2005, No. 34(8), pp. 1128-1149.

[10] P. Cooke, M.G. Uranga, \& G. Etxebarria. Regional innovation systems: Institutional and organizational dimensions. Research Policy, 1997, No. 26 (4-5), pp. 475-491.

[11] D. Doloreux, and S. Parto. Regional innovation systems: a critical review, ERSA Conference Papers, 2004.

[12] S. Iammarino. An evolutionary integrated view of regional systems of innovation: Concepts, measures and historical perspectives. European Planning Studies, 2005, No. 13(4), pp. 497-519.

[13] B. Lengyel, \& L. Leydesdorff. Regional innovation systems in Hungary: The failing synergy at the national level. Regional Studies, 2011, No. 45(5), pp. 677-693.

[14] L. Leydesdorff. The triple helix, quadruple helix, ..., and an N-tuple of helices: explanatory models for analyzing the knowledge-based economy? Journal of the Knowledge Economy, 2012, No. 3(1), pp. 25-35.

[15] L. Leydesdorff, \& M. Fritsch. Measuring the knowledge base of regional innovation systems in Germany in terms of a triple helix dynamics. Research Policy, 2006, No. 35(10), pp. 1538-1553.

[16] R.M. Pino, \& A.M. Ortega. Regional innovation systems: Systematic literature review and recommendations for future research. Cogent Business \& Management, 2018, 5(1).

[17] Ponsiglione, I. Quinto and G. Zollo. Regional Innovation Systems as Complex Adaptive Systems: The Case of Lagging European regions. - Sustainability, 2018, 10, 2862.

[18] S.L. Zhao, L. Cacciolatti, S.H. Lee, W. Song. Regional collaborations and indigenous innovation capabilities in China: A multivariate method for the analysis of regional innovation systems. Technological Forecasting and Social Change, 2014, No. 94. pp. 202220.

[19] D. Morkovkin, S. Shmanev, L. Shmaneva. Problems and Trends in Innovative Transformation of Russian Economy and Infrastructure Development // Proceedings of the 3rd International Conference on Economics, Management, Law and Education (EMLE 2017) / Advances in Economics Business and Management Research. 2017. Volume 32, pp. 10-13. 